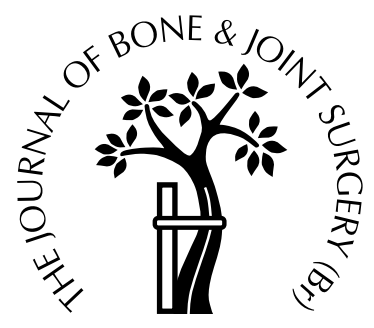

\title{
Therapeutic embolisation for postoperative haemorrhage after total arthroplasty of the hip and knee
}

\author{
A. Barriga, J. R. Valentí Nin, C. Delgado, J. J. Bilbao \\ From the Clinica Universitaria de Navarra, Pamplona, Spain
}

$\mathbf{W}$ e describe three cases of postoperative haemorrhage, two after total hip and one after total knee replacement, treated by percutaneous embolisation. After diagnostic angiography, this is the preferred method for the treatment of postoperative haemorrhage due to the formation of a false aneurysm, after hip or knee arthroplasty. This procedure, carried out under local anaesthesia, has a low rate of complications and avoids the uncertainty of further surgical exploration.

J Bone Joint Surg [Br] 2001;83-B:90-2.

Received 14 June 2000; Accepted 24 July 2000

Vascular complications of total hip or knee arthroplasty are rare but because of the increasing number of these operations and of revision procedures the incidence is rising. ${ }^{1-1}$ These problems are associated with considerable morbidity, particularly if they are undiagnosed or if treatment is delayed. $2,6,9,12$

Percutaneous transcatheter embolisation of a false aneurysm associated with joint replacement surgery is a useful alternative to operative excision, and allows a simple resolution of postoperative haemorrhage. $1,3,4,7,8,10,11,13-20$

We describe three cases of postoperative bleeding, two after total hip and one after total knee replacement.

\section{Case reports}

Case 1. An 81-year-old man had had a cemented right total hip replacement 20 months previously. This was removed 15 months later because of deep infection. He received appropriate antibiotic treatment until the infection was controlled and underwent a revision procedure with a further cemented implant using the same lateral approach as

A. Barriga, MD, Resident

J. R. Valentí Nin, MD, Head of Department

Department of Orthopaedic Surgery and Traumatology

C. Delgado, MD, Consultant Radiologist

J. J. Bilbao, MD, Head of Department

Department of Radiology

Clínica Universitaria de Navarra, Pio XII, 3631008 Pamplona, Spain.

Correspondence should be sent to Dr J. Valentí Nin.

(C)2001 British Editorial Society of Bone and Joint Surgery 0301-620X/01/111458\$2.00 had been used for the initial surgery. The drains were removed two days after operation. Mobilisation began on the sixth day and was followed by brisk haemorrhage which continued despite rest and local compression. Arteriography using a size 4 French Cobra catheter (Cordis, Rhoden, The Netherlands) via the contralateral femoral artery, revealed a false aneurysm of the posterior circumflex artery (Figs 1a and 1b). Selective catheterisation of the afferent artery was undertaken with embolisation using $3 \mathrm{~mm}$ coils (Cook, Bjaeverskov, Denmark) and the arterial lesion was 'packed' using small pieces of Gelfoam. Follow-up arteriography showed complete obliteration of the artery (Fig. 1c). The patient did well after the procedure and was discharged after 20 days.

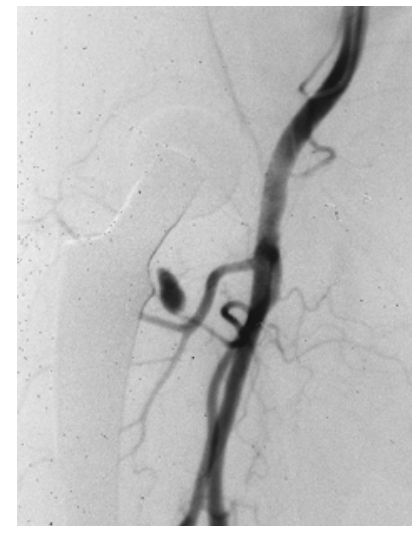

Fig. 1a

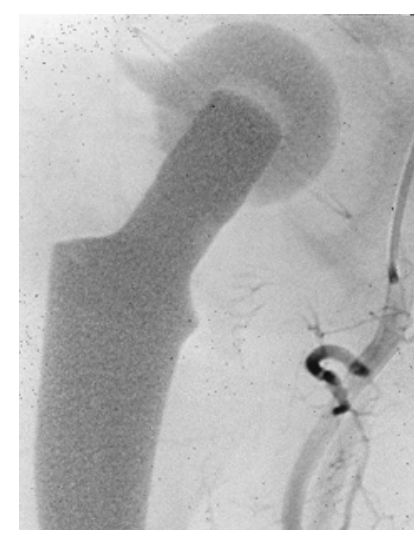

Fig. 1c

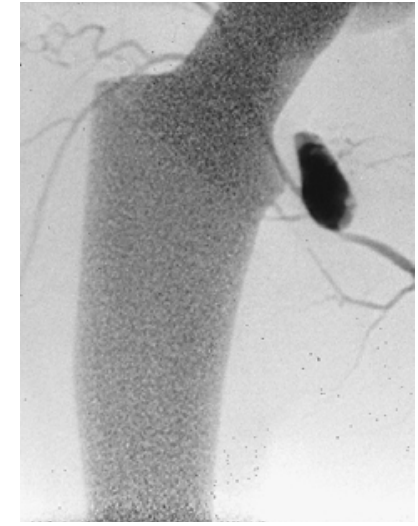

Fig. 1b
Case 1 - Arteriograms showing a) a false aneurysm of the posterior circumflex artery, b) a massive leak with distal flow through an efferent vessel and c) complete obliteration of the false aneurysm after embolisation. 


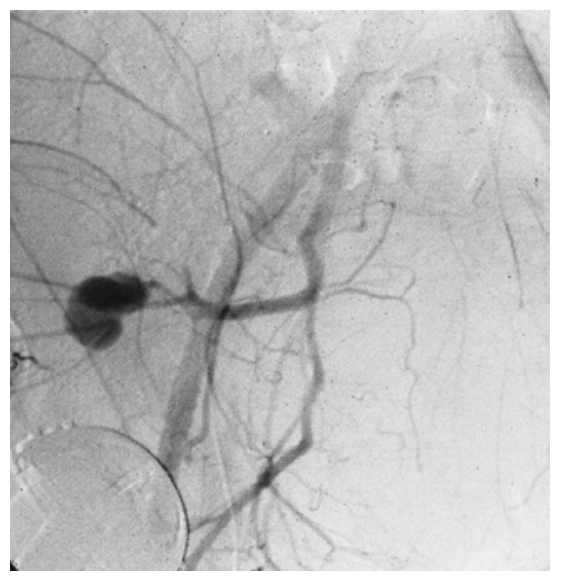

Fig. 2a

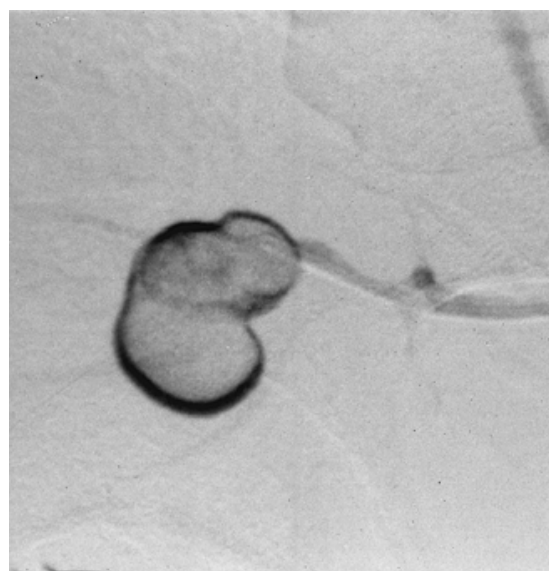

Fig. $2 b$

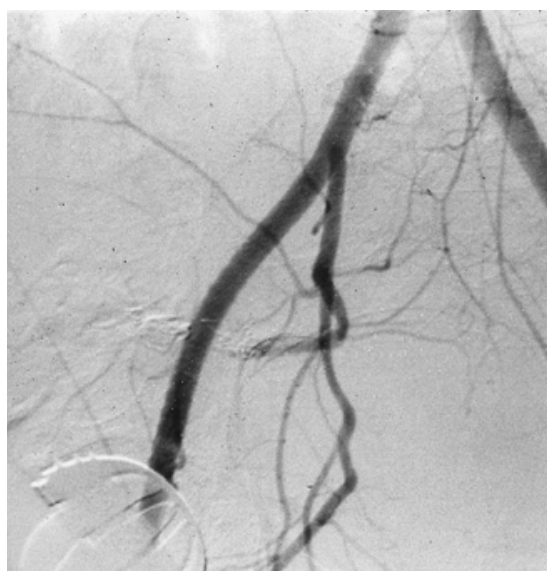

Fig. 2c

Case 2 - Arteriograms showing a) selective catheterisation of the superior gluteal artery which identifies a rapid flow aneurysm originating from a single afferent vessel, b) a $4 \mathrm{~F}$ catheter inside the afferent vessel (there is no visualisation of contrast leak through any efferent vessel) and c) the placement of multiple coils along the afferent vessel and superior gluteal artery.

Case 2. A 47-year-old man with avascular necrosis of the right hip had an uncemented total hip replacement using a lateral approach without complications. Massive fresh haemorrhage began on the third postoperative day. Arteriography using a Pigtail catheter (Cordis, Rhoden, The Netherlands) introduced into the left femoral artery revealed a false aneurysm of a muscular branch of the superior gluteal artery (Figs $2 \mathrm{a}$ and $2 \mathrm{~b}$ ). Selective catheterisation was undertaken with embolisation using 3 and $5 \mathrm{~mm}$ multiple coils (Cook, Bjaeverskov, Denmark) in the afferent superior gluteal arteries. Follow-up arteriography showed no further haemorrhage; the patient did well and was discharged 11 days later (Fig. 2c).
Case 3. A 73-year-old man presented with osteoarthritis of his left knee having undergone a high tibial osteotomy nine years previously with a satisfactory result. Total knee replacement with a stabilised prosthesis was undertaken without complications. Fresh haemorrhage developed on the fourth postoperative day and selective arteriography of the left superficial femoral artery revealed a large false aneurysm of the lateral superior genicular artery (Fig. 3a). The afferent vessel was catheterised with a size 4 French Cobra catheter and the lesion was occluded with three $3 \mathrm{~mm}$ coils (Fig. 3b). Arteriography after embolisation showed no further extravasation (Fig. 3c). The patient did well and was discharged 16 days later.

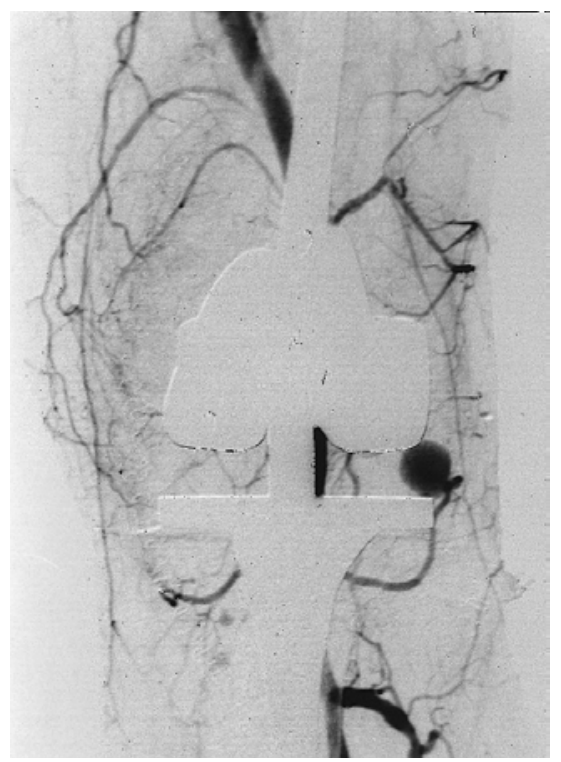

Fig. 3a

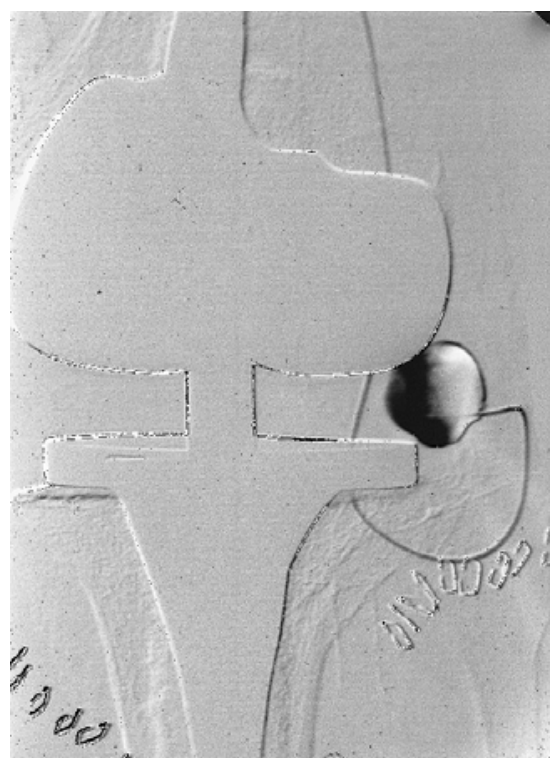

Fig. $3 b$

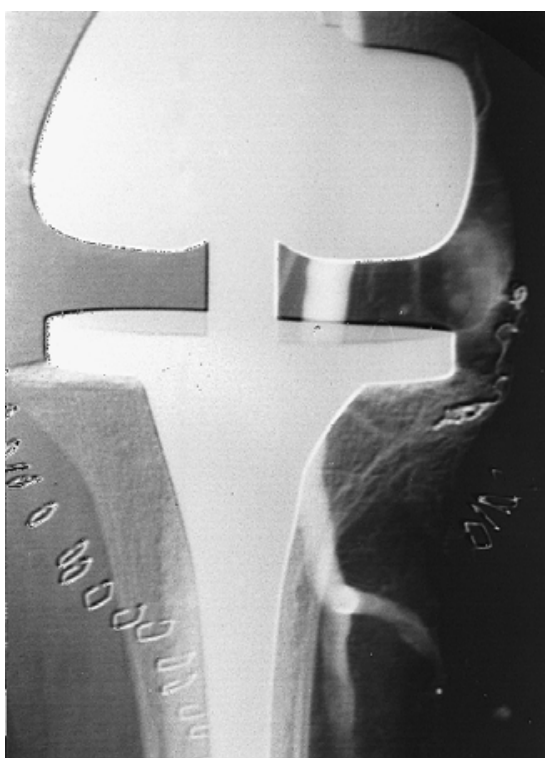

Fig. 3c

Case 3 - Arteriograms showing a) a large false aneurysm of the superior lateral genicular artery, b) a microcatheter inside the afferent vessel and c) complete obliteration of the false aneurysm after the placement of multiple coils in the afferent vessel. 


\section{Discussion}

Although vascular injuries after total hip or knee replacement are rare they may threaten both life and limb.

Several mechanisms of vascular injury have been described including perforation of an artery by a retractor, injury to an artherosclerotic artery with the subsequent formation of a thrombus induced by perioperative manoeuvres of the joint, by a tourniquet, by direct trauma to a vessel, a vascular injury secondary to the heat of polymerisation of methylmethacrylate and a false aneurysm or arteriovenous fistula induced by repeated local trauma. ${ }^{2,6}$

Exact knowledge of the relationship of the neurovascular structures within the surgical field is essential to prevent these injuries. $2,3,6,17,18,21$ The use of blunt rounded retractors is recommended.

In revision of a total hip arthroplasty with marked acetabular protrusion preoperative angiography may be used to identify the relationship of the acetabular component to the neurovascular structures within the pelvis. ${ }^{6}$

Early recognition of a vascular injury is essential, although sometimes its presentation may be delayed. Severe pain, a pulsatile mass with decreasing haemoglobin levels or fresh bleeding, usually through the drains, are indications of a vascular complication. $2,6,11,18,21$

Embolisation is preceded by diagnostic angiography, usually using a contralateral approach. ${ }^{15,16}$ The exact anatomy of the lesion requiring treatment must be fully identified. Once the site of haemorrhage has been demonstrated it is necessary to establish that there is distal flow to the lesion and that only one vessel is involved so that effective embolisation may be planned. Embolisation, carried out as selectively as possible, improves the chances of success and reduces the risk of complications such as ischaemia of neighbouring structures. There are many embolic agents which give good results, but the most widely used, as in our cases, are gelatin sponges and coils. ${ }^{14-16,20}$

No benefits in any form have been received or will be received from a commercial party rleated directly or indirectly to the subject of this article.

\section{References}

1. Bennett JD, Brown TC, Coates CF, MacKenzie D, Sweeney J. Pseudoaneurysm of the inferior gluteal artery. Can Assoc Radiol J 1992;43:296-8.
2. Bergqvist D, Carlsson AS, Ericsson BF. Vascular complications after total hip arthroplasty. Acta Orthop Scand 1983;54:157-63.

3. De Groof E, Violon D, Hermans P, Boghemans J. Bleeding from the lateral circumflex artery following total hip replacement, treated by embolization. Acta Orthop Belg 1994;60:231-4.

4. Dejean O, Hardy P, Raufaste D, Benoit J. Embolisation of the circumflex femoral artery for recurrent haemorrhage after total hip arthroplasty: a proposal of a case. Rev Chir Orthop Reparatrice Appar Mot 1992;78:201-4.

5. Holmberg A, Milbrink J, Bergqvist D. Arterial complications after knee arthroplasty: 4 cases and a review of the literature. Acta Orthop Scand 1996;67:75-8.

6. Mallory TH, Jaffe SL, Eberle RW. False aneurysm of the common femoral artery after total hip arthroplasty. Clin Orthop 1997;338:105-8

7. Omary R, Stulberg D, Vogelzang RL. Therapeutic embolization of false aneurysms of the superior medial genicular artery after operation of the knee: a report of two cases. J Bone Joint Surg [Am] 1991;73-A:1257-9.

8. Oppenheim WL, Harley JD, Lippert FG III. Arteriographic management of postoperative bleeding following major hip surgery: case report. J Bone Joint Surg [Am] 1975;57-A:127-8.

9. Pina Medina A, Pardo Montaner J. Desarticulación de cadera por lesión vascular tras protrusión acetabular de una prótesis total de cadera. Rev Ortop Traumatol 1996;40:474-7.

10. Shoenfeld NA, Stuchin SA, Pearl R, Haveson S. The management of vascular injuries associated with total hip arthroplasty. J Vasc Surg 1990;11:549-55.

11. Stock JR, Athanasoulis CA, Harris WH, et al. Transcatheter embolization for the control of wound hemorrhage following hip surgery. $J$ Bone Joint Surg [Am] 1980;62-A:1000-3.

12. Dearborn JT, Harris WH. Postoperative mortality after total hip arthroplasty: an analysis of deaths after two thousand seven hundred and thirty-six procedures. J Bone Joint Surg [Am] 1998;80-A:12914.

13. Allison DJ. Therapeutic embolisation. J Bone Joint Surg [Br] 1982;64-B:151-2.

14. Cope C, Zeit R. Coagulation of aneurysms by direct percutaneous thrombin injection. AJR Am J Roentgenol 1986;147:383-7.

15. Jackson JE, Mitchell A. Advanced vascular interventional techniques in the management of trauma. Sem Interventional Radiol 1997; $14: 139-50$

16. Kidney DD. The endovascular approach to trauma. In: Dyet JF, Nicholson AA, Ettles DF, Wilson SE, eds. Textbook of endovascular procedures. Philadelphia: Churchill Livingstone, 2000:313-22.

17. Rickman M, Saleh M, Gaines PA, Eyres K. Vascular complications of osteotomies in limb reconstruction. J Bone Joint Surg [Br] 1999;81-B:890-2.

18. Stanley D, Cumberland DC, Elson RA. Embolisation for aneurysm after knee replacement. J Bone Joint Surg [Br] 1989;71-B:138.

19. Walker TG, Geller SC, Brewster DC. Transcatheter occlusion of a profunda femoral artery pseudoaneurysm using thrombin. AJR Am J Roentgenol 1987;149:185-6.

20. Malleaux G, Stockx L, Brys P, et al. Iatrogenic pseudoaneurysm in the upper arm: treatment by transcatheter embolization. Cardiovas Intervent Radiol 2000;23:140-3.

21. Sarrosa EA, Ogilvie-Harris DJ. Pseudoaneurysm as a complication of knee arthroscopy. Arthroscopy 1997;13:644-5. 